\title{
Regulation AND the Legal Profession
}

\author{
JOHN M. LAW*
}

You will be pleased to know that my closing comments will be brief for two reasons: first, we have come to the end of an intense day of sessions; and second, time does not permit an intensive analysis of our panel's presentations, which I believe speak for themselves.

To begin with, I wish to thank all the members of the panel for their thoughtful and interesting presentations which have offered us a number of perspectives on the regulation of lawyers, particularly self-regulation. They have enriched our understanding of the salient issues and have clearly demonstrated that the regulation of lawyers is a very difficult and complex question, particularly for an increasingly fragmented and stratified profession.

Having said that, let me make a couple of brief comments about the regulation of lawyers. In this respect, I am afraid to say that to a significant number of lawyers, self-governance or regulation is not a matter of controversy; rather, it is the natural order of things. That is, the regulation of lawyers, by lawyers, for lawyers (or should that read "for the public"?) is deeply woven into the fabric of the profession's identity. Self-regulation has long been considered to be one of the defining attributes or characteristics of a profession, and as law is considered to be the paradigmatic profession, it must, of course, be self-regulating. Without self-regulation or governance, law would no longer be a profession, but simply a regulated, or unregulated, occupation. Therefore, a legal profession, without powers of selfregulation, is beyond the contemplation or imagination of many, if not most, lawyers. For that reason, few lawyers reflect on the purpose or efficacy of self-regulation in its current form or, for that matter, its continuance, except to defend it vigorously when under attack, or bemoan the public's lack of understanding about the need for, and effectiveness of, the current scheme.

Yet reflect we must. Canada stands almost alone in its reliance on self-regulation as a means of governance through the structure of provincial law societies. As each member of our panel has indicated in his remarks, professional self-regulation is not a given and, indeed, has undergone reconsideration recently in a number of major common law jurisdictions, such as England and Wales, and New Zealand. In these and other jurisdictions, self-regulation has been, or will be, replaced by a form of co-regulation in which the professional organization, such as the law society, makes and implements rules to govern lawyer behaviour and performance, and enforces these standards through discipline processes, all subject to government oversight and, where necessary, government intervention.

Such a change would not have occurred had there not been significant concern that the traditional structures of self-regulation had failed to serve the public interest. While Duncan Webb $^{1}$ suggests in his article that these "reforms" are unlikely to have any significant impact on lawyer regulation, which will remain, one way or another, "lawyer-centric," the mere fact of government oversight of lawyer regulation in other jurisdictions, that is, the loss of 
complete regulatory autonomy, suggests that similar changes may be coming to Canada and that lawyers in this country ought to pay more attention to the issue of self-regulation of the profession and whether it will continue as the primary model of lawyer regulation well into this century, let alone the next.

The success of regulatory change in other jurisdictions will prompt a reconsideration of the traditional scheme of lawyer self-regulation in Canada, and if lawyers wish to retain regulatory autonomy, then they must be prepared to rationally argue and defend the proposition that the current model best serves the public interest, that the benefits of selfregulation outweigh its social and economic costs.

I believe it will not simply be a question of tinkering with the historic structure or model of regulation, or more vigorously defending the status quo through often rhetorical arguments based on the importance of lawyer independence or expertise. Such arguments are perceived by many to be self-serving justifications for a situation of professional privilege reflected in market dominance and regulatory unaccountability. A public increasingly skeptical about social, political, and economic institutions, will have to be convinced, by both word and deed, that the regulation of lawyers by lawyers serves the public's interests rather than lawyers' interests.

That takes me to my final point, which concerns the public interest. As Michael J. Trebilcock and others have pointed out, the public interest or welfare (in his view, "to maximize net consumer welfare" ${ }^{\text {"2 }}$ ) must form the centrepiece of any regulatory scheme. The regulation of lawyers should not be carried out in the furtherance of their individual or collective interests; it must be undertaken in the furtherance of the public interest in accessible, ethical, and quality legal services.

While it has long been suggested that the promotion of the profession's interests can coexist with the protection of the public's interests, we know that not to be the case and the public knows or believes that it is not the case! The public is rightly cynical, or skeptical, about the ability of a regulatory regime, made up almost entirely of lawyers, to identify and vigorously pursue the public interest. For example, many Canadians cannot easily access or afford the services of a lawyer, and yet we do not see the profession press government for more law school spaces or for the accommodation of paralegal service providers in the market for legal services. Is the public interest in quality legal services best served in all cases by a licensing scheme which restricts entry to those who have undergone at least seven years of formal university education and one year of practical training of variable quality? Maybe something less, or different, would suffice to meet the needs of many Canadians for quality legal services?

Moreover, the discipline process, and its underlying rules and standards, seems focused on unethical conduct - is that what most consumers of legal services are concerned about? From the growing number of complaints to law societies about the performance of lawyers, it would seem that the public is more concerned about the quality and cost of legal services 
than it is about the ethical conduct of lawyers. The historic focus of law societies on entry qualifications and discipline seems to be an ill fit with public concerns about the poor quality of legal services.

I could go on and on in this respect, but I believe the point is clear: the profession needs to better serve the public interest and, in this respect, needs to better understand what the interests of the public are. Law, as a self-governing profession needs to better engage the public, both in terms of identifying public needs and being accountable to it. The public ought to be involved in the setting of ethical and practice standards, the public ought to play a larger role in the complaint and discipline processes, and the public ought to be informed widely and often about the profession's governance principles and practices.

Greater public participation in the regulation of the profession has been advocated by one of our panel members, and despite the problems of "regulatory capture," such participation ought to be undertaken as a clear signal of the profession's commitment to regulation in the public interest.

Finally, if the public interest requires, on the basis of a rational analysis of costs and benefits, the implementation of a different model or scheme of regulation, such as those outlined by Richard Devlin and Porter Heffernan ${ }^{3}$ in their discussion of a more nuanced, flexible, calibrated form of regulation, then we should be open to it and to our possible role in it as a public profession committed, in word and in deed, to service in the public interest.

The reference to "service in the public interest" seems as good a place as any to conclude my brief remarks. Service in the public interest will be the challenge for self-regulation in the future, near and far; a challenge that must be addressed through an informed assessment of the issues and rational decision-making, marked by an openness to new structures and models of governance, and aware, in a modest way, of the inherent limitations of selfregulation.

On behalf of the panelists, thank you for your attention. 